\title{
Análisis de la estructura primaria y secundaria del ARN de transferencia mitocondrial para serina en siete especies de Lutzomyia
}

\author{
Rafael José Vivero, Maria Angélica Contreras-Gutiérrez, Eduar Elías Bejarano
}

Grupo de Investigaciones Biomédicas, Universidad de Sucre, Sincelejo, Colombia.

Introducción. Los insectos del género Lutzomyia son los responsables de la transmisión del parásito Leishmania spp. en América. La taxonomía de estos vectores se fundamenta en los caracteres morfológicos que exhiben los adultos, principalmente, en las estructuras pareadas de la cabeza y los genitales. Aunque estos caracteres permiten distinguir la mayoría de los taxones, la similitud en algunos subgéneros y grupos de especies pone límites a la identificación por criterios morfológicos.

Objetivo. Evaluar la utilidad del ARN de transferencia mitocondrial para serina ARNtser en la determinación taxonómica de Lutzomyia.

Materiales y métodos. Se analizaron siete especies flebotomíneas, $L$. trinidadensis, $L$. panamensis, L. cayennensis cayennensis, L. dubitans, L. gomezi, L. rangeliana y L. evansi. A partir de cada individuo, se extrajo, amplificó y obtuvo la secuencia del gen mitocondrial que codifica para el $A R N t^{\text {Ser }}$, delimitado por los genes citocromo b y NAD deshidrogenasa uno. La estructura secundaria del $\mathrm{ARNt}^{\mathrm{Ser}}$ se infirió teniendo como base las estructuras homólogas descritas en otros insectos del orden Diptera.

Resultados. La longitud del gen ARNtSer osciló entre 66 pb en L. gomezi y 69 pb en $L$. trinidadensis. En el alineamiento nucleotídico de 70 posiciones, se detectaron 14 sitios polimórficos, incluyendo cuatro eventos indel. La mayoría de las sustituciones correspondieron a las lupas dihidrouridina, ribotimidina-pseudouridina-citosina y variable, así como al extremo basal del brazo anticodón.

Conclusión. Los cambios en la secuencia primaria de nucleótidos y los rearreglos en la estructura secundaria del $\mathrm{ARNt} \mathrm{t}^{\text {Ser }}$ son potencialmente útiles para la discriminación taxonómica de las especies flebotomíneas estudiadas.

Palabras clave: Psychodidae/clasificación, ARN de transferencia/genética, mitocondria, ADN, leishmaniasis.

Analysis of the primary and secondary structure of the mitochondrial serine transfer RNA in seven species of Lutzomyia

Introduction. Lutzomyia sand flies are involved in the transmission of the parasite Leishmania spp. in America. The taxonomy of these vectors is traditionally based on morphological features of the adult stage, particularly the paired structures of the head and genitalia. Although these characters are useful to distinguish most species of Lutzomyia, morphological identification may be complicated by the similarities within subgenera and species group.

Objective. To evaluate the utility of mitochondrial serine transfer RNA tRNA ${ }^{\text {Ser }}$ for taxonomic identification of Lutzomyia.

Materials and methods. Seven sand fly species, each representing one of the 27 taxonomic subdivisions in genus Lutzomyia, were analyzed including L. trinidadensis (Oswaldoi group), L. (Psychodopygus) panamensis, L.(Micropygomyia) cayennensis cayennensis, L. dubitans (Migonei group), L. (Lutzomyia) gomezi, L. rangeliana (ungrouped) and L. evansi (Verrucarum group). The mitochondrial tRNA ${ }^{\text {Ser }}$ gene, flanked by the cytochrome $b$ and NAD dehydrogenase subunit one genes, was extracted, amplified and sequenced from each specimen. Secondary structure of the tRNA ${ }^{\text {ser }}$ was predicted by comparisons with previously described homologous structures from other dipteran species. 
Results. The tRNA ${ }^{\text {Ser }}$ gene ranged in size from 66 base pairs in $L$. gomezi to 69 base pairs in $L$. trinidadensis. Fourteen polymorphic sites, including four insertion-deletion events, were observed in the aligned 70 nucleotide positions. The majority of the substitutions were located in the dihydrouridine, ribothymidine-pseudouridine-cytosine and variable loops, as well as in the basal extreme of the anticodon arm.

Conclusion. Changes of primary sequence of the tRNA ${ }^{\text {ser }}$ provided useful molecular characters for taxonomic identification of the sand fly species under consideration.

Key words: Psychodidae/classification, RNA transfer/genetics, mitochondria, DNA, leishmaniasis.

Los flebotomíneos son un grupo de insectos de reconocida importancia en el ámbito de la salud pública debido a su papel fundamental en el mantenimiento del ciclo de vida del parásito Leishmania, agente etiológico de la leishmaniosis (1). Estos dípteros también tienen la capacidad de transmitir bacterias y virus a los humanos (2).

El reconocimiento morfológico de los flebotomíneos se basa en su cuerpo hirsuto y pequeño, alas lanceoladas con 10 venas longitudinales y pocas venas transversales, patas relativamente largas y aparato bucal adaptado a la hematofagia. Su taxonomía está sustentada, casi exclusivamente, en los caracteres morfológicos que exhiben los adultos, debido a las dificultades para localizar los estados inmaduros en la naturaleza (3). En los machos, la determinación de la especie se realiza a partir de las estructuras pareadas de los genitales y la cabeza, mientras que las hembras pueden separarse por los apéndices cefálicos, la armadura cibarial y la forma de las espermatecas (4). En ambos sexos también son útiles la pigmentación del tórax y los índices del ala, entre otros rasgos (5).

Si bien estos caracteres permiten distinguir la mayoría de los taxones, la similitud morfológica en algunos subgéneros y grupos de especies, pone límites a la identificación por criterios morfológicos. Esto ha propiciado la búsqueda de métodos alternativos de determinación de especie, entre los cuales se encuentran los

Correspondencia:

Eduar E. Bejarano, Centro de Diagnóstico Médico, Universidad de Sucre, Carrera 14 No. 16B-32, apartado aéreo 406, Sincelejo, Colombia.

Teléfono: (575) 2820830; fax: (575) 2821240.

eduarelias@yahoo.com

Recibido:31/01/07; aceptado: 19/06/07 caracteres moleculares (6,7). Las secuencias de nucleótidos se destacan principalmente por su abundancia, al considerar cada posición nucleotídica como un carácter con cuatro estados posibles (adenina, guanina, citosina y timina o uracilo), el cual permite detectar diversidad antes no percibida por otros marcadores, en adición a su discreción reflejada en estados de carácter no ambiguos (8). No obstante, la mayoría de los estudios moleculares de flebotomíneos parten de la identificación taxonómica derivada de caracteres morfológicos, la cual se realiza en las especies americanas usando las claves taxonómicas de Young y Perkins (9), Young y Duncan (4), y Galati (5).

El genoma mitocondrial es un marcador útil, tanto para estudios de población como filogenéticos, debido a que contiene segmentos con diferentes dinámicas de mutación (7). Éste se compone de una región control, 13 genes codificadores de proteínas, dos genes que codifican para las subunidades ribosomales y 22 genes para ARN de transferencia (ARNt) (10). En estudios taxonómicos, tanto interespecíficos como intraespecíficos del género Lutzomyia França, 1924, se han usado los genes citocromo b, citocromo oxidasa I, NAD deshidrogenasa 1 y 4 y la subunidad pequeña ribosomal (11-17), que en conjunto representan sólo el $13 \%$ de la diversidad de genes de la molécula mitocondrial.

Los ARNt desarrollan un papel central en la biosíntesis proteica y son un componente esencial altamente conservado en todos los sistemas biológicos; esto los convierte en una herramienta atractiva para los estudios de evolución molecular (18-20). Inicialmente, los ARNt se sintetizan como moléculas monocatenarias de $A R N$, que adquieren luego la apariencia de hoja de trébol, 
en las que se distinguen motivos como el brazo aceptor del aminoácido, el brazo y la lupa dihidrouridina (DHU), el brazo y la lupa del anticodón, la lupa variable, y el brazo y la lupa ribotimidina-pseudouridina-citosina (T $\psi \mathrm{C})(21)$.

A pesar de que en las bases de datos moleculares disponibles en línea se encuentran depositadas algunas secuencias nucleotídicas de ARNt de flebotomíneos, no se conocían hasta la fecha estudios sobre la estructura secundaria de ARNt que operan en la mitocondria de este importante grupo taxonómico. En el presente trabajo se evaluó la utilidad de la estructura secundaria de un ARNt mitocondrial en la discriminación de siete especies del género Lutzomyia.

\section{Materiales y métodos}

\section{Recolección y determinación taxonómica de flebotomíneos}

Los flebotomíneos se recolectaron en el perímetro urbano del municipio de Sincelejo $\left(9^{\circ} 18^{\prime} \mathrm{N}, 75^{\circ} 25^{\prime}\right.$ W), departamento de Sucre. La clasificación ecológica de la zona corresponde a bosque seco tropical, con precipitaciones anuales de $1.050 \mathrm{~mm}$ y una temperatura promedio anual de $28^{\circ} \mathrm{C}$. La captura de los insectos se efectuó entre las 18:00 y 06:00 horas, empleando dos trampas de luz de tipo CDC (Centers for Disease Control and Prevention) instaladas en el intradomicilio y el peridomicilio. Los muestreos entomológicos se realizaron cuatro veces por semana, durante los meses de febrero a noviembre del año 2005.

Los ejemplares recolectados se examinaron bajo el estereoscopio con el fin de separar la cabeza, un ala y los tres últimos segmentos abdominales, que se usaron para la identificación taxonómica, luego de ser aclarados durante 24 horas en una solución de lactofenol (ácido láctico y fenol, en proporción 1:1) y montados en láminas portaobjeto con el medio de Hoyer. El tórax, un ala, las patas y el resto del abdomen se usaron para extraer el material genético. En total, se recolectaron e identificaron 512 flebotomíneos pertenecientes al género Lutzomyia usando las claves de Young y Duncan (4) y Galati (5). El esquema taxonómico seleccionado corresponde al propuesto por Young y Duncan (4). Los montajes entomológicos se encuentran depositados en la Colección de Artrópodos de Importancia Médica de la Universidad de Sucre-CAIMUS, en Sincelejo, Colombia.

\section{Extracción del ADN genómico}

La extracción del ADN se desarrolló de acuerdo con el protocolo de Collins et al. (22), con las siguientes modificaciones. Los segmentos corporales seleccionados de cada individuo se maceraron con micropistilos estériles en $60 \mu \mathrm{l}$ de la solución tampón de lisis $(0,08 \mathrm{NaCl}, 0,16 \mathrm{M}$ sacarosa, 0,06 M EDTA, 0,5\% SDS, 0,1 M Tris$\mathrm{HCL}$ a pH de 7,5), incubando a una temperatura de $65^{\circ} \mathrm{C}$ por 30 minutos. La precipitación de proteínas se realizó con $14 \mu \mathrm{l}$ de acetato de potasio $8 \mathrm{M}$ durante 30 minutos sobre hielo, seguido de centrifugación a $12.000 \mathrm{~g}$ durante 10 minutos. EI ADN presente en el sobrenadante se precipitó con $200 \mu \mathrm{l}$ de etanol absoluto, incubando a $-20^{\circ} \mathrm{C}$ durante 24 horas. Cada muestra se centrifugó a $12.000 \mathrm{~g}$ durante 20 minutos y el ácido nucleico precipitado en el fondo del vial se lavó con $200 \mu \mathrm{l}$ de etanol al $70 \%$ y, luego, con $200 \mu \mathrm{l}$ de etanol absoluto. Finalmente, se secó el ADN a temperatura ambiente y se resuspendió en $30 \mu \mathrm{l}$ de agua ultrapura. De la solución anterior, se extrajeron $10 \mu \mathrm{l}$ para una electroforesis en gel de agarosa al $1 \%$, con el fin de constatar la cantidad y calidad del ADN obtenido.

\section{PCR y secuenciación de nucleótidos}

Para el estudio se seleccionó el gen que codifica para el ARNt mitocondrial para serina (UCN) (ARNtser). La amplificación del ADN se realizó con los oligonucleótidos CB3FC- sentido (CA(T/ C)ATTCAACC (A/T)GAATGATA) y NINFRantisentido (GGTA(C/T)(A/T)TTGCCTCGA(T/ A)TTCG(T/A)TATGA), cuya secuencia es complementaria al extremo 3' del gen citocromo b y 3' del gen NAD deshidrogenasa uno (NAD1), respectivamente, flanqueando el gen $A R N t^{S e r}$ (11). El gen NAD1 es uno de los transcritos del genoma mitocondrial que tienen como hebra codificadora a la cadena $\mathrm{H}$; por lo tanto, la secuencia de los ARN derivados de esta cadena se transcribe en dirección contraria a la de los genes citocromo $b$ y ARNt ${ }^{\mathrm{Ser}}$. 
La reacción en cadena de la polimerasa (PCR) se desarrolló en un volumen de $50 \mu \mathrm{l}$, que contenían $0,3 \mathrm{mM}$ de cada cebador, solución tampón de PCR $1 \mathrm{x}, 3 \mu \mathrm{M}$ de $\mathrm{MgCl}_{2}, 0,2 \mathrm{mM}$ de la mezcla de desoxirribonucleósidos trifosfatos (dNTP), 1,5 U de Taq ADN polimerasa y $8 \mu$ le la solución con el ADN extraído. Las condiciones de amplificación consistieron en una etapa inicial de desnaturalización a $94^{\circ} \mathrm{C}$ por 3 minutos, una segunda etapa de 35 ciclos, que incluyó desnaturalización a $93^{\circ} \mathrm{C}$ por 1 minuto, alineamiento a $50^{\circ} \mathrm{C}$ por 1 minuto y extensión a $72^{\circ} \mathrm{C}$ por 1 minuto, finalizando con una tercera etapa de elongación a $72^{\circ} \mathrm{C}$ durante 10 minutos. El producto de la PCR se verificó mediante electroforesis en gel de agarosa y se purificó usando Wizard PCR Preps (Promega). La secuencia nucleotídica del fragmento amplificado se determinó en ambos sentidos de la doble hebra de ADN, en un secuenciador automático de electroforesis capilar ABI $3730 x \mathrm{xl}$, que emplea cuatro dideoxinucleótidos terminadores de cadena marcados con grupos fluorescentes.

\section{Análisis molecular}

El análisis genético se realizó con el programa MEGA 3.1 (23) a partir de la secuencia nucleotídica consenso del gen $A R N t^{S e r}$ por espécimen, la cual se derivó de las secuencias obtenidas de cada hebra de ADN. Para el alineamiento múltiple de las secuencias se usó el algoritmo Clustal W (24) integrado en MEGA 3.1 en la opción Alignment Explorer/CLUSTAL, que permitió identificar los sitios nucleotídicos variables en el grupo de especies estudiadas. Con la herramienta BLASTN (alineamiento nucleótido-nucleótido) (25) disponible en línea, se determinó el porcentaje de similitud y la posición de las secuencias obtenidas respecto al genoma mitocondrial de otros insectos. El programa MEGA 3.1 también se usó para calcular la composición nucleotídica de cada uno de los siete taxones analizados. La hipotética estructura secundaria del $A R \mathrm{Nt}^{\mathrm{Ser}}$ se infirió manualmente a partir del grupo de secuencias alineadas, sugerido como un método apropiado por Klingler y Brutlag (26), teniendo en cuenta, además, las estructuras homólogas descritas previamente en organismos del orden Diptera $(26,27)$. La estructura secundaria obtenida se comparó luego con la producida por el programa tRNAscan-SE 1.21 (28). Finalmente, todas las secuencias nucleotídicas generadas en el presente estudio están depositadas en GenBank con los números de acceso del EF012215 al EF012225 (cuadro 1).

\section{Resultados}

Se obtuvieron 11 secuencias nucleotídicas completas del gen mitocondrial $\mathrm{ARNt}^{\mathrm{Ser}}$ de siete especies de Lutzomyia determinadas taxonómicamente como hembras de $L$. trinidadensis (Newstead, 1922), L. panamensis (Shannon, 1926), L. cayennensis cayennensis (Floch y Abonnenc, 1941), L. dubitans (Sherlock, 1962), L. gomezi (Nitzulescu, 1931), L. rangeliana (Ortíz, 1952) y L. evansi (Núñez-Tovar, 1924)

Cuadro 1. Números de acceso en Genbank y de registro en la colección entomológica CAIMUS de las siete especies del género Lutzomyia estudiadas.

\begin{tabular}{|c|c|c|c|c|}
\hline Especie & $\begin{array}{l}\text { Subgénero o } \\
\text { grupo de especies }\end{array}$ & $\begin{array}{l}\text { Cantidad de } \\
\text { aislados }\end{array}$ & $\begin{array}{c}\text { Número de acceso } \\
\text { GenBank }\end{array}$ & $\begin{array}{c}\text { Número de registro } \\
\text { CAIMUS }\end{array}$ \\
\hline L. trinidadensis & Grupo oswaldoi & 1 & EF012215 & P173 \\
\hline L. panamensis & Subgénero Psychodopygus & 2 & EF012216 & P93 \\
\hline L. cayennensis $C$ & Subgénero Micropygomyia & 2 & $\begin{array}{l}\text { EF012218 } \\
\text { EF012219 }\end{array}$ & $\begin{array}{l}\text { P54 } \\
\text { P512 }\end{array}$ \\
\hline L. dubitans & Grupo migonei & 1 & EF012220 & P158 \\
\hline L. gomezi & Subgénero Lutzomyia & 2 & $\begin{array}{l}\text { EF012221 } \\
\text { EF012222 }\end{array}$ & $\begin{array}{l}\text { P5 } \\
\text { P7 }\end{array}$ \\
\hline L. rangeliana & No agrupada & 2 & $\begin{array}{l}\text { EF012223 } \\
\text { EF012224 }\end{array}$ & $\begin{array}{l}\text { P108 } \\
\text { P118 }\end{array}$ \\
\hline L. evansi & Grupo verrucarum & 1 & EF012225 & P59 \\
\hline
\end{tabular}


(cuadro 1). El segmento secuenciado es homólogo a la región comprendida entre las posiciones 11585 y 11653 del genoma mitocondrial de Aedes albopictus (número de acceso NC_006817, GenBank).

El análisis molecular del gen $\mathrm{ARNt}^{\mathrm{Ser}}$ de los taxones estudiados se basó en 70 posiciones nucleotídicas producto del alineamiento múltiple (figura 1). El carácter económico de la molécula mitocondrial se manifiesta en L. cayennensis cayennensis y $L$. rangeliana por el solapamiento de la primera base nucleotídica, adenina, del gen $\mathrm{ARNt}^{\mathrm{Ser}}$, con la última base del codón de terminación del gen citocromo $b$, y se acentúa más en L. gomezi, donde estos genes comparten dos nucleótidos, adenina y guanina. Aunque se secuenció más de un individuo de $L$. panamensis, $L$. cayennensis cayennensis, L. gomeziy L. rangeliana (cuadro 1), se observó un solo haplotipo nucleotídico para cada una de estas especies. La frecuencia nucleotídica en todas las especies se caracterizó por un alto contenido de adenina (42,4\%) y timina (39\%), contrastando con un bajo porcentaje de guanina $(10,2 \%)$ y citosina ( $8,4 \%)$. La secuencia del gen ARNt ${ }^{S e r}$ osciló en tamaño entre 66 pb en
L. gomezi y 69 pb en L. trinidadensis, manteniéndose en este rango $L$. dubitans, $L$. evansi y $L u$. cayennensis cayennensis con una extensión de 67 pb, además de L. panamensis y L. rangeliana con un tamaño de $68 \mathrm{pb}$.

La estructura secundaria del ARNtSer inferida inicialmente de forma manual fue idéntica a la producida por el programa tRNAscan-SE, el cual arrojó una sola estructura posible para cada una de las especies estudiadas. La longitud superior del ARNt ${ }^{S e r}$ de L. trinidadensis se debe al tamaño de la lupa $T \psi C$ que aparece constituida por nueve bases (figura 2A), a diferencia de las demás especies cuya extensión se mantuvo en el rango de 6 a 8 bases. Del mismo modo, la reducción en el tamaño del ARNtser de L. gomezi es producto de la pérdida de tres bases en la lupa $T \psi C$ (figura 2B). El número de apareamientos del tipo WatsonCrick (guanina-citosina y adenina-uracilo) en el grupo de taxones fluctuó entre 4 y 5 en el brazo del anticodón, 7 en el brazo aceptor, 3 y 4 en el brazo DHU, y 4 y 5 en el brazo T $\psi \mathrm{C}$ (figuras $2 \mathrm{~A}$ $2 \mathrm{G})$. Todas las especies se caracterizaron por la presencia de dos bases entre el brazo aceptor y el brazo DHU, una base entre este último y el

Posiciones nucleotídicas

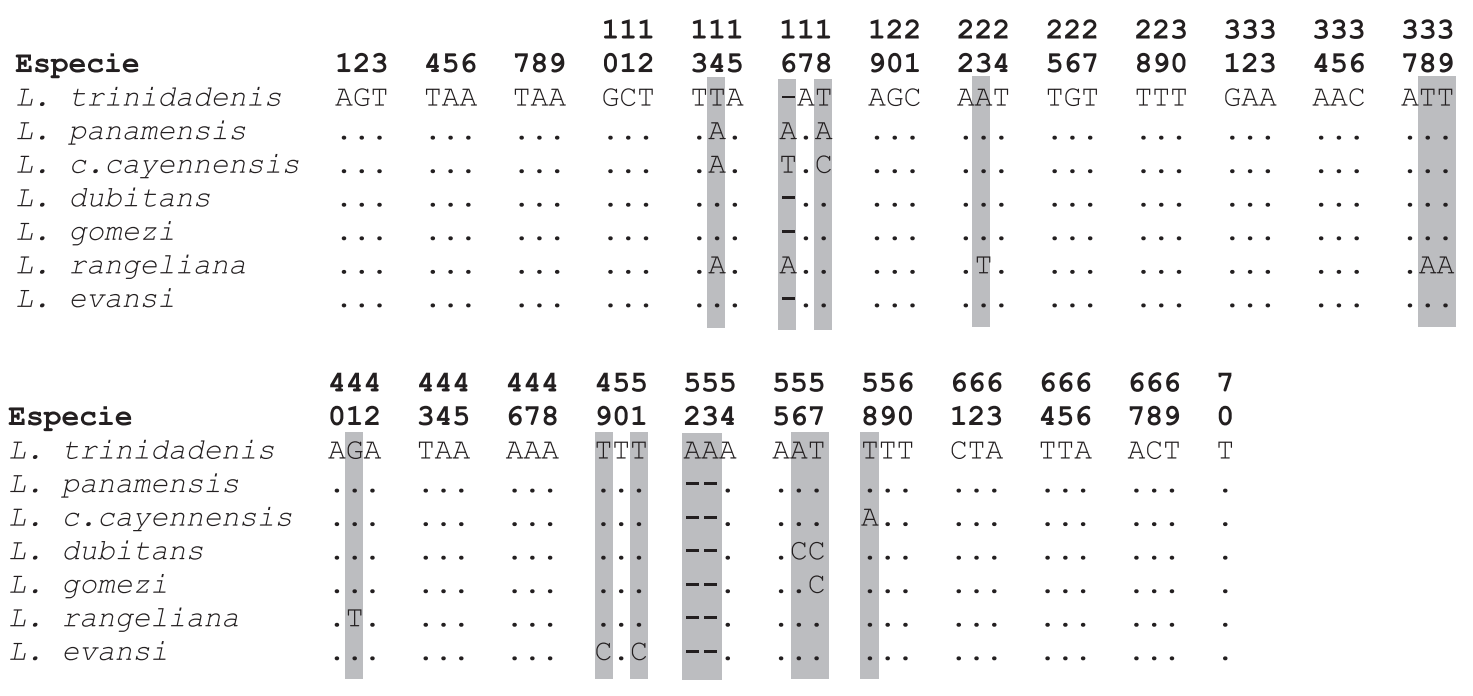

Figura 1. Alineamiento múltiple de las secuencias del gen mitocondrial ARNt ${ }^{S e r}$ de siete especies del género Lutzomyia. Los puntos indican homología y los guiones corresponden a eventos indel (inserción-delección). Los nucleótidos sombreados resaltan los sitios polimórficos de la secuencias. 

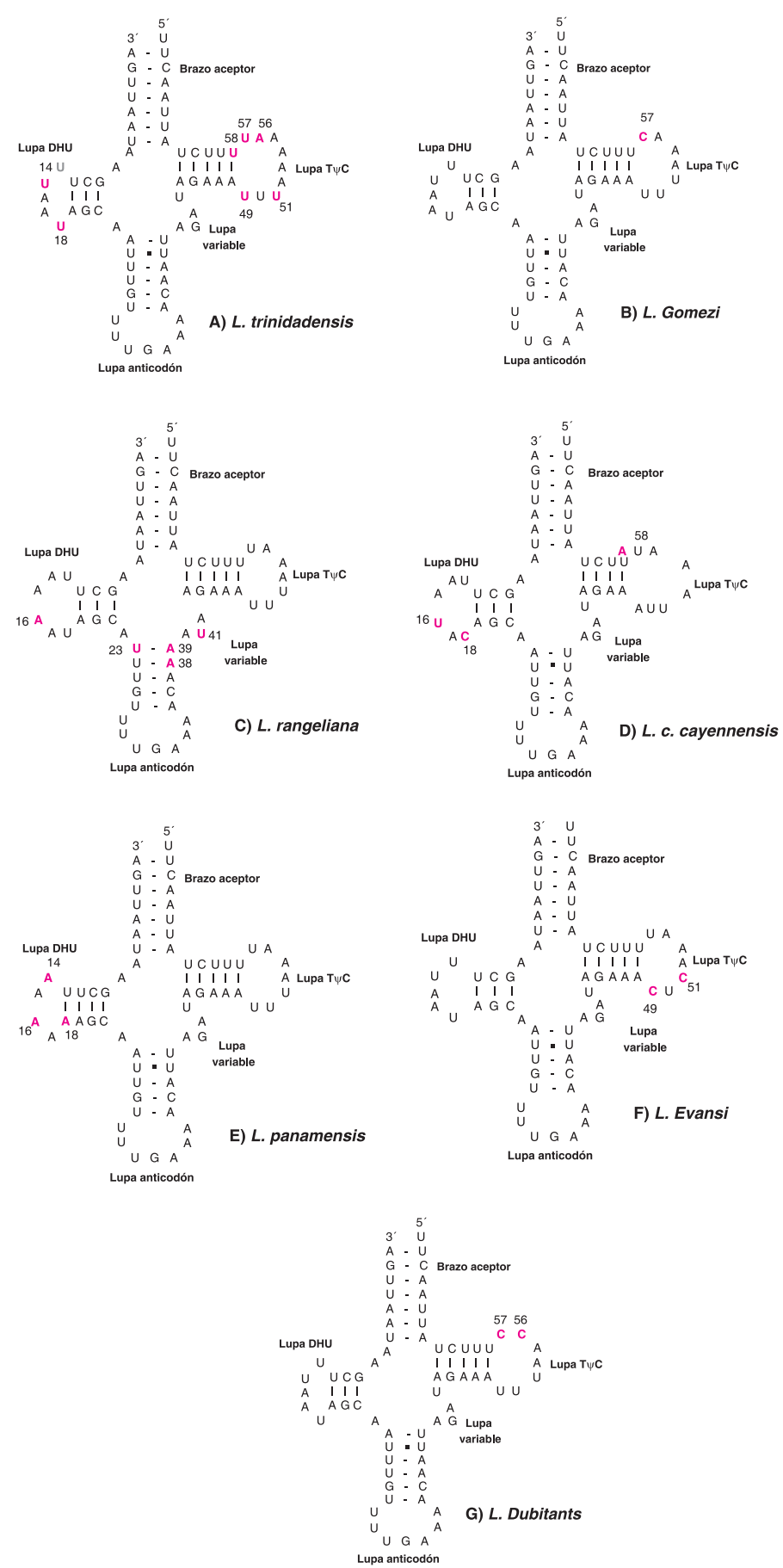

Figura 2. Predicción de la estructura secundaria del gen $A R N t^{S e r}$ de siete especies del género Lutzomyia: A) L. trinidadensis, B) L. rangeliana, C) L. panamensis, D) L. cayennensis cayennensis, E) L. dubitans, F) L. gomezi, G) L. evansi. Las letras en color rojo denotan las bases distintivas de cada especie y el número relaciona la posición en el alineamiento múltiple de las secuencias. Los apareamientos Watson-Crick se representan con barras y los apareamientos no Watson-Crick se indican con puntos. 
brazo del anticodón y cuatro bases en la lupa variable.

En el alineamiento se observaron 14 sitios nucleotídicos polimórficos, incluyendo cuatro eventos indel (inserción-delección), que corresponden a una tasa de variación global de $20 \%$ (figura 1). Sin embargo, los valores pareados de divergencia entre especies variaron entre $2,86 \%$, observado entre L. dubitans y L. gomezi, y $11,43 \%$, encontrado al comparar $L$. rangeliana con $L$. trinidadensis, $L$. cayennensis cayennensis, $L$. dubitans, L. evansi y L. gomezi. Al confrontar las secuencias de nucleótidos del gen $\mathrm{ARNt}^{\mathrm{Ser}}$ de las siete especies estudiadas con secuencias homólogas de flebotomíneos depositadas en Genbank, se obtuvieron porcentajes de similitud que oscilaron entre $88 \%$ y $98 \%$. Estos corresponden a los valores encontrados entre $L$. evansi y L. ovallesi (Ortíz, 1952) (AF403487) y L. rangeliana y $L$. nuneztovari (Ortiz, 1954) (AF403491), respectivamente.

La mayoría de las sustituciones correspondieron a las lupas $\mathrm{DHU}, \mathrm{T} \psi \mathrm{C}$ y variable, así como al extremo basal del brazo anticodón, en los cuales se encontraron posiciones con nucleótidos propios de cada especie flebotomínea. En $L$. rangeliana es notoria la presencia de cinco apareamientos Watson-Crick en el brazo del anticodón, derivado de la sustitución del uracilo por la adenina en la posición 38 (figura $2 \mathrm{C}$ ), en tanto que las demás especies poseen cuatro apareamientos WatsonCrick y un apareamiento no Watson-Crick. Esta especie también se destaca por la presencia de los nucleótidos uracilo, adenina y uracilo en las posiciones 23 y 39 del mismo brazo y la posición 41 de la lupa variable, respectivamente (figura 2C).

A diferencia de los otros taxones que exhiben cinco apareamientos canónicos en el brazo $\mathrm{T} \psi \mathrm{C}$, L. cayennensis cayennensis posee sólo cuatro apareamientos Watson-Crick (figura 2D), como producto del reemplazo del uracilo en la posición 58 por adenina, la cual genera un apareamiento no canónico en el interior de dicha estructura. Igualmente, esta especie se distingue por la presencia de uracilo y citosina en los sitios 16 y 18 , respectivamente, de la lupa DHU. $L$. panamensis tiene el brazo DHU más largo, con 4 pb y la lupa DHU más corta, con sólo 4 bases (figura 2E), mientras los otros taxones exhiben tres apareamientos Watson-Crick en dicho brazo y 5 o 6 bases en la misma lupa. Esta especie también se caracteriza por mostrar una adenina en la posición 18 de la lupa DHU (figura 2E), además de compartir la adenina de la posición 14 con $L$. cayennensis cayennensis y de las posiciones 14 y 16 con L. rangeliana. En L. evansi es exclusiva la presencia de la base citosina en los sitios 49 y 51 de la lupa $T \psi C$ (figura 2F). De otro lado, la presencia de dos citosinas de forma consecutiva en las posiciones 56 y 57 de la lupa $T \psi C$ es una característica distintiva de $L$. dubitans (figura 2G), que comparte a su vez esta última base con L. gomezi.

\section{Discusión}

En el genoma mitocondrial de los metazoos se encuentran presentes dos genes que codifican para el $A R N t^{S e r}(A G N)$ y $A R N t^{S e r}(U C N)$, el último de los cuales se caracterizó en este estudio. Aunque en los bancos de datos moleculares reposan algunas secuencias nucleotídicas del gen mitocondrial ARNt ${ }^{\text {Ser }}$ para flebotomíneos del Nuevo y el Viejo Mundo, no se había evaluado a la fecha, la utilidad de la estructura secundaria del ARNtSer para el diagnóstico de especies de este grupo taxonómico.

El porcentaje de conservación global de $80 \%$, observado entre las secuencias nucleotídicas del gen mitocondrial $A R N t^{S e r}$ de las siete especies de Lutzomyia estudiadas, puede ser consecuencia de restricciones operacionales que hacen imperiosa la conservación de la estructura secundaria de este ARNt (10). Más aún, las regiones que aparecen estructuralmente conservadas, como el brazo aceptor del aminoácido, el brazo DHU, la lupa del anticodón y el brazo $\mathrm{T} \psi \mathrm{C}$, estarían revelando la importancia funcional que tienen dichos motivos en el ARNtSer de los flebotomíneos. La conservación del gen se hace más notoria al examinar los porcentajes pareados de similitud, los cuales estuvieron en el rango de $88 \%$ a $98 \%$, incluyendo la comparación con las especies flebotomíneas registradas en Genbank. Es importante anotar que L. rangeliana aportó gran parte del polimorfismo observado. 
La mayoría de los caracteres nucleotídicos variables se expresaron a lo largo de las lupas $\mathrm{DHU}$, T $\psi C$ y variable, con la excepción de los cambios observados en los primeros nucleótidos del brazo del anticodón de $L$. rangeliana que originaron un apareamiento Watson-Crick adicional. Esto permite deducir que tales regiones gozan de mayor libertad para mutar en estos insectos, particularmente las lupas $\mathrm{DHU}$ y $\mathrm{T} \psi \mathrm{C}$ que sufrieron la mayor parte de las sustituciones. Además, llama la atención que las divergencias en longitud entre las especies tengan origen en estas lupas y no en la lupa variable, cuyo tamaño fue constante en todos los taxones, aunque en la mayoría de los animales es la directa responsable de los diferencias de tamaño entre los $\mathrm{ARNt}$ Ser mitocondriales.

Es importante destacar que todos los apareamientos observados en los distintos brazos del $\mathrm{ARNt}^{\mathrm{Ser}}$ de $L$. rangeliana fueron del tipo WatsonCrick, sobresaliendo entre el grupo de especies estudiadas como la única que carece de apareamientos no canónicos. Los últimos determinan en gran parte la complejidad estructural de los ARNt, participando activamente en los procesos de reconocimiento molecular RNA-RNA y RNA-proteínas. No obstante, se requieren más estudios para determinar la importancia de este hallazgo.

Las sustituciones nucleotídicas observadas en la secuencia del gen $\mathrm{ARNt}^{\mathrm{Ser}}$ y los rearreglos estructurales ocasionados por éstas, son útiles para la correcta distinción de cada uno de los flebotomíneos estudiados, sumado a las diferencias en el tamaño del gen por la pérdida o ganancia de bases. La extensión nucleotídica del gen $\mathrm{ARNt}^{\mathrm{Ser}}$ en Lutzomyia, comprendida en el rango de 66 a 69 bases, es ligeramente inferior al margen de 68 a 70 bases encontrado al comparar el mismo gen en especies flebotomíneas del género Phlebotomus del Viejo Mundo (29) (números de acceso en Genbank, U94474, U94473 y U94471).

Los patrones de cambio genético parecen inclinarse a favor de la teoría de la evolución con tendencia a la reducción, reflejada en la disminución del número de bases nucleotídicas y, por consiguiente, en la disminución del tamaño de los elementos que integran el genoma mitocondrial. Esto podría explicar el solapamiento de la secuencia del gen ARNt ${ }^{\text {Ser }}$ con el gen citocromo $b$ en $L$. cayennensis cayennensis, $L$. rangeliana y $L$. gomezi, poniendo en evidencia el carácter económico de la molécula mitocondrial. También se ha sugerido que los ARNt adyacentes a genes codificadores de proteínas pueden desempeñar un papel de puntuación en el procesamiento de éstas (30).

En la escala zoológica, se ha observado un acortamiento gradual de algunos ARNt mitocondriales, como la desaparición del brazo DHU en el ARNt ${ }^{\text {Ser }}$ (AGY) (10). La seril ARNt sintetasa que carga el aminoácido serina al extremo 3'OH del $\mathrm{ARNt}^{\mathrm{Ser}}$ se clasifica como tipo II; por lo tanto, su reconocimiento se basa principalmente en la forma y el tamaño distintivo de la estructura secundaria, a diferencia de las aminoacil ARNt sintentasas tipo I, en las cuales los residuos del la lupa anticodón y del brazo aceptor son importantes para el reconocimiento del ARNt. Por esto, es más tolerable una reducción que un aumento del tamaño del $A R N t^{S e r}$, considerando que lo último posiblemente dificultaría el acoplamiento de la molécula al bolsillo activo de la seril ARNt sintetasa.

Desde el punto de vista del tamaño, $L$. trinidadensis podría postularse como la especie más ancestral dentro del grupo de flebotomíneos estudiados por presentar el gen $\mathrm{ARNt}^{\mathrm{Ser}}$ más largo. Esto se sustenta además, según los estudios morfológicos, por la presencia de una espermateca lisa sin anulaciones terminales y de cinco espinas estilares dispuestas en los genitales masculinos que, de acuerdo con Theodor (31), corresponden a la forma primitiva de la que eventualmente se derivaron el resto de especies flebotomíneas americanas. Sin embargo, esta hipótesis de evolución molecular del $\mathrm{ARNt}^{\mathrm{Ser}}$ en Lutzomyia deberá ser evaluada en futuros estudios mediante la incorporación de otras especies que poseen cinco espinas estilares.

Teniendo en cuenta que los resultados de esta investigación comprueban la utilidad de la estructura primaria y secundaria del tRNA ${ }^{\text {Ser }}$ para 
la discriminación taxonómica de flebotomíneos, se sugiere ampliar el análisis incluyendo más individuos de las mismas especies, así como otros taxones de origen neotropical. Más aún, por su tasa evolutiva éste podría ser un marcador molecular apropiado para evaluar las relaciones filogenéticas entre los subgéneros y grupos de especies de flebotomíneos americanos.

\section{Agradecimientos}

A los biólogos Alveiro Pérez-Doria y Luz Fernanda Lambraño por el suministro de algunos flebotomíneos. A los revisores anónimos por sus valiosos comentarios que contribuyeron a la mejora del manuscrito.

\section{Conflicto de intereses}

Los autores declaran que no existe conflicto de interés alguno sobre el estudio publicado.

\section{Financiación}

Este trabajo fue financiado por el Grupo de Investigaciones Biomédicas de la Universidad de Sucre.

\section{Referencias}

1. Montoya-Lerma J, Ferro C. Flebótomos (Diptera: Psychodidae) de Colombia. En: Amat G, Andrade MG, Fernández $F$, editores. Insectos de Colombia. Volúmen II. Colección Jorge Álvarez Lleras, No. 13. Academia Colombiana de Ciencias Exactas, Físicas y Naturales. Bogotá D. C.: Centro Editorial Javeriano; 1999. p.211-45.

2. Sherlock IA. Importância dos flebotomíneos. En: Rangel EF, Lainson R, editores. Flebotomíneos do Brasil. Rio do Janeiro: Editora Fiocruz; 2003. p.15-21.

3. Brazil RP, Brazil BG. Biología de flebotomíneos neotropicais. En: Rangel EF, Lainson R, editores. Flebotomíneos do Brasil. Rio do Janeiro: Editora Fiocruz; 2003. p.257-74.

4. Young DG, Duncan MA. Guide to the identification and geographic distribution of Lutzomyia sand flies in Mexico, the West Indies, Central and South America (Diptera: Psychodidae). Mem Amer Ent Inst. 1994;54:1881.

5. Galati EA. Morfologia, terminologia de adultos e identificação dos táxons da América. En: Rangel EF, Lainson R, editores. Flebotomíneos do Brasil. Rio do Janeiro: Editora Fiocruz; 2003. p.53-175.

6. Bejarano EE. Sobre la evolución de los flebotomíneos americanos (Diptera: Psychodidae): un llamado a los sistemáticos moleculares. Rev Colomb Entomol. 2002;28:211-2.
7. Bejarano EE. Nuevas herramientas para la clasificación taxonómica de los insectos vectores de leishmaniosis: utilidad de los genes mitocondriales. Biomédica. $2001 ; 21: 182-91$.

8. Avise JC. Molecular markers, natural history and evolution. $1^{\text {st }}$ ed. New York: Chapman \& Hall Inc; 1994. p.1-511.

9. Young DG, Perkins PV. Phlebotomine sand flies of North America (Diptera: Psychodidae). Mosq News. 1984;44:263-304.

10. Simon C, Frati F, Beckenbach A, Crespi B, Liu H, Flook P. Evolution, weighting, and phylogenetic utility of mitochondrial gene sequences and a compilation of conserved polymerase chain reaction primers. Ann Entomol Soc Am. 1994;87:651-701.

11. Ready PD, Day JC, De Souza AA, Rangel EF, Davies CR. Mitochondrial DNA characterization of populations of Lutzomyia whitmani (Diptera: Psychodidae) incriminated in the peri-domestic and silvatic transmission of Leishmania species in Brazil. Bull Entom Res. 1997;87:187-95.

12. Bejarano EE. Variabilidad genética y especiación en Lutzomyia (verrucarum) evansi (Núñez-Tovar, 1924), vector de leishmaniosis visceral americana [Tesis]. Medellín: Universidad de Antioquia; 2001.

13. Soto SI, Lehmann T, Rowton ED, Vélez ID, Porter $\mathbf{C H}$. Speciation and population structure in the morphospecies Lutzomyia longipalpis (Lutz \& Neiva) as derived from the mitochondrial ND4 gene. Mol Phylogenet Evol. 2001;18:84-93.

14. Rojas W. Relaciones filogenéticas en Lutzomyia spp. del grupo verrucarum (tesis). Medellín: Universidad de Antioquia; 2001.

15. Arrivillaga JC, Norris DE, Feliciangeli MD, Lanzaro GC. Phylogeography of the neotropical sand fly Lutzomyia longipalpis inferred from mitochondrial DNA sequences. Infect Genet Evol. 2002;2:83-95.

16. Testa JM, Montoya-Lerma J, Cadena H, Oviedo M, Ready PD. Molecular identification of vectors of Leishmania in Colombia: Mitochondrial introgression in the Lutzomyia townsendi series. Acta Trop. 2002;84: 205-18.

17. Beati L, Caceres AG, Lee JA, Munstermann LE. Systematic relationships among Lutzomyia sand flies (Diptera: Psychodidae) of Perú and Colombia based on the analysis of $12 \mathrm{~S}$ and $28 \mathrm{~S}$ ribosomal DNA sequences. Int J Parasitol. 2004;34:225-34.

18. Rich A, Schimmel PR. Structural organization of complexes of transfer RNAs with aminoacyl transfer RNA synthetases. Nucleic Acids Res. 1977; 4:1649-65.

19. Masta SE. Mitochondrial sequence evolution in spiders: intraspecific variation in tRNAs lacking the TCC arm. Mol Biol Evol. 2000;17:1091-100. 
20. Chandra BC, Jennifer L, Kapatral V. Comparative insect mitochondrial genomes: Differences despite conserved genome synteny Sathees. Afr J Biotechnol. 2006,5:1308-18.

21. Lodish H, Baltimore D, Berk A, Lawrence S, Matsudaira P, Darnell J. Molecular cell biology. $3^{\text {rd }}$ ed. New York: Scientific American Books Inc; 1995. p.11344.

22. Collins FH, Mendez MA, Rasmussen MO, Mehaffey PC, Besansky NJ, Finnerty V. A ribosomal RNA gene probe differentiates member species of the Anopheles gambiae complex. Am J Trop Med Hyg. 1987;37:37-41.

23. Kumar S, Tamura K, Nei M. MEGA 3.1: Integrated software for molecular evolutionary genetics analysis and sequence alignment. Brief Bioinform. 2004;5:150-63.

24. Thompson JD, Higgins DG, Gibson TJ. CLUSTAL $W$ : improving the sensitivity of progressive multiple sequence alignment through sequence weighting, position-specific gap penalties and weight matrix choice. Nucleic Acids Res. 1994;22:4673-80.

25. Altschul SF, Gish W, Miller W, Myers EW, Lipman DJ. Basic local alignment search tool. J Mol Biol. 1990;215:403-10.
26. Klingler TM, Brutlag DL. Detection of correlations in tRNA sequences with structural implications. Proc Int Conf Intell Syst Mol Biol. 1993;1:225-33.

27. Beard CB, Hamm DM, Collins FH. The mitochondrial genome of the mosquito Anopheles gambiae: DNA sequence, genome organization, and comparisons with mitochondrial sequences of other insects. Insect $\mathrm{Mol}$ Biol. 1993;2:103-24.

28. Lowe TM, Eddy SR. tRNAscan-SE: a program for improved detection of transfer RNA genes in genomic sequence. Nucleic Acids Res. 1997;25:955-64.

29. Esseghir S, Ready PD, Killick-Kendrick R, BenIsmail R. Mitochondrial haplotypes and phylogeography of Phlebotomus vectors of Leishmania major. Insect Mol Biol. 1997;6:211-25.

30. Ojala D, Montoya J, Attardi G. tRNA punctuation model of RNA processing in human mitochondria. Nature. $1981 ; 290: 470-4$.

31. Theodor 0 . On the classification of American Phlebotominae. J Med Entomol. 1965;2:171-97. 